\title{
COMMENTARY
}

\section{Accessing marine protists from the anoxic Cariaco Basin}

\author{
V Edgcomb, W Orsi, GT Taylor, P Vdacny, C Taylor, P Suarez and S Epstein
}

The ISME Journal (2011) 5, 1237-1241; doi:10.1038/ ismej.2011.10; published online 10 March 2011

The earliest microbial cells evolved in an anoxic ocean (Martin and Muller, 1998), and many argue that the earliest Eukarya arose in the absence of oxygen as well. The microbe-mediated biogeochemical processes taking place below oxic/anoxic interfaces are of undeniable importance and interest, and the Cariaco Basin off the coast of Venezuela is a superb model ecosystem in this regard. It is the world's largest body of truly marine anoxic waters and has been almost continuously anoxic for at least the last 2M years (Schubert, 1982). Consequently, the Basin became the site of many investigations, including a long-term biogeochemical time series initiated in 1995 (Muller-Karger et al., 2001; Taylor et al., 2001) and an NSF-funded Microbial Observatory established in 2004. This Observatory was a multi-year, multi-investigator international effort. Its principal goals were:

- to combine molecular and cell-based approaches to survey microbial Eukarya among geochemically diverse habitats in the Basin;

- to analyze the community structure and its dynamics across time and space;

- to discover novel organisms, and to gain insights into what governs their distribution dispersal and biogeography.

Overall, this observatory became arguably the largest exploration of protistan life in a single geographic location to date. We summarize its key results in two papers published in this issue (Edgcomb et al., 2011; Orsi et al., 2011). Although the data on protists in the Basin presented in the graphs, phylogenetic trees and statistical plots of these papers tell some interesting stories, other intriguing and sometimes unexpected observations also deserve mention. Although such observations may not support firm conclusions, they can provide important insights into protistan ecology and help guide future research, as discussed in this Commentary.

From the beginning, a major goal was to step beyond sequence-based discovery, and, having identified interesting 18S ribosomal RNA (rRNA) gene signatures, to get hold of the novel species, preferably in the form of their cultures. However, all the samples brought to the surface from below the oxic/anoxic interface, typically positioned at a depth of $250 \mathrm{~m}$, remained lifeless. Despite the utmost precautions to avoid exposure to oxygen, or to minimize shifts in pressure, no protists ever grew.

This challenge turned into an opportunity to develop a sampling device to capture and fix the cells in situ, something that apparently had not been done before, at least for microbial eukaryotes. A modified deep-sea fixation device (Taylor and Doherty, 1990) enabled preservation of cells in situ with glutaraldehyde for scanning electron microscopy (SEM) and with Bouin's solution for combined fluorescent in situ hybridization (FISH)-SEM analysis (Stoeck et al., 2003a). Although the resulting cells were dead, and thus still not cultivable, it was now possible to see them in all their glory (Figures 1a-i, and also the cover of this issue).

This approach revealed an abundance of apparently novel protists from anoxic waters of the Cariaco Basin, whose novel morphologies reflected the divergent 18S rRNA gene sequences found below the oxic/anoxic interface (Edgcomb et al., 2011; Orsi et al., 2011). A large number of small cells had spherical shapes that did not leave much room for interpretation. However, cells exhibiting more complex morphology showed unique features. Some examples include nanoflagellates that possessed conspicuously long flagella almost five times longer than their body (Figure 1c), and what appeared to be cryptomonad flagellates exhibited a furrow extending from the vestibulum to the posterior body end (Figure 1a). We also observed numerous ciliates, sharing with the known scuticociliates their prominent paroral membrane and one to several caudal cilia. As common for anaerobic ciliates, these species were covered with morphologically diverse epibiotic bacteria (Figures 1e-i, and also the cover of this issue).

The observed flagellates and ciliates confirmed that at least some protists detected from anoxic depths by the rRNA gene approach were not dead: their cells were not collapsed as would be expected of naked cells upon death, and the presence of putative symbionts suggested activity. A complementary DNA (cDNA) approach brought another 

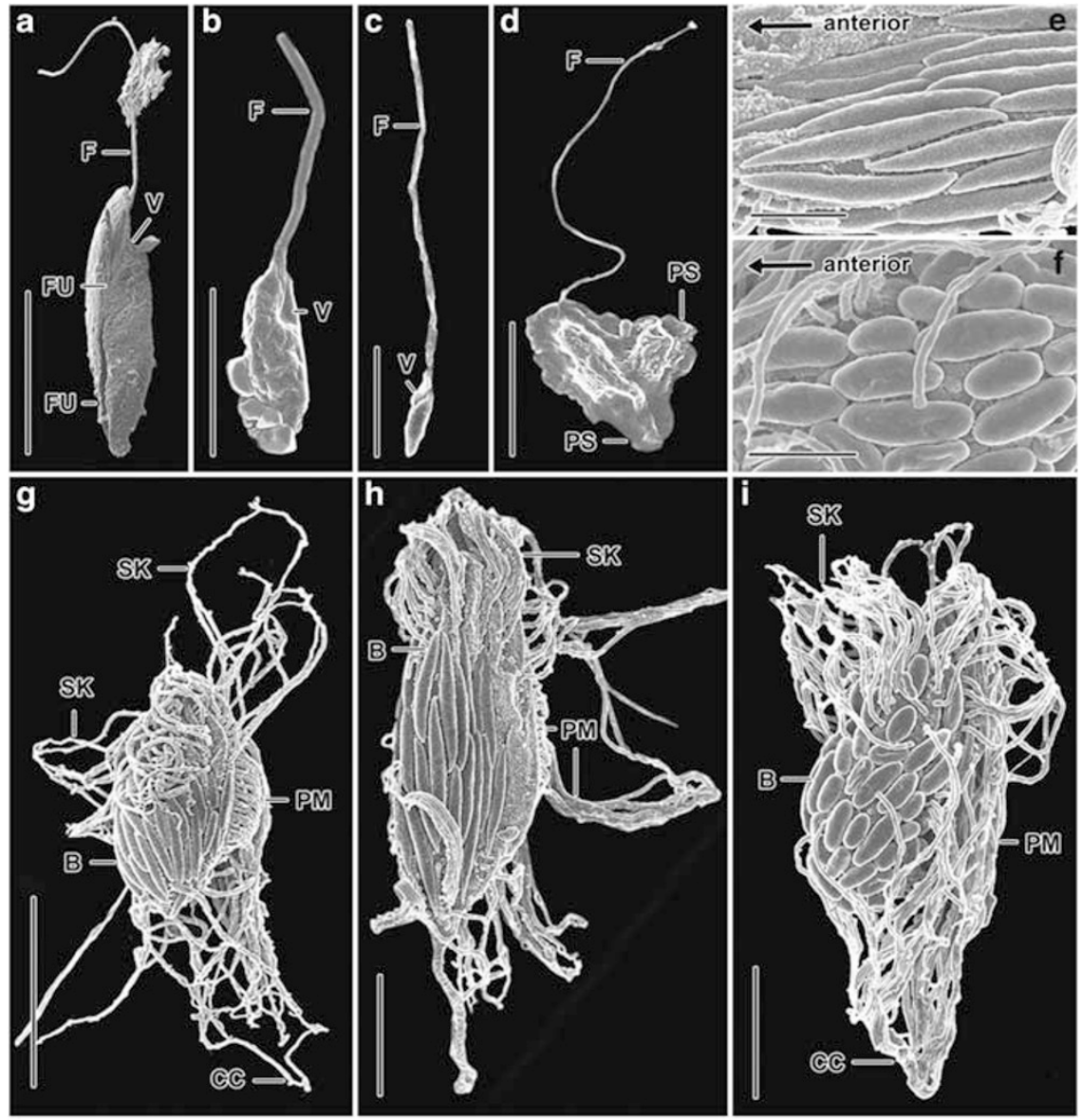

j 6

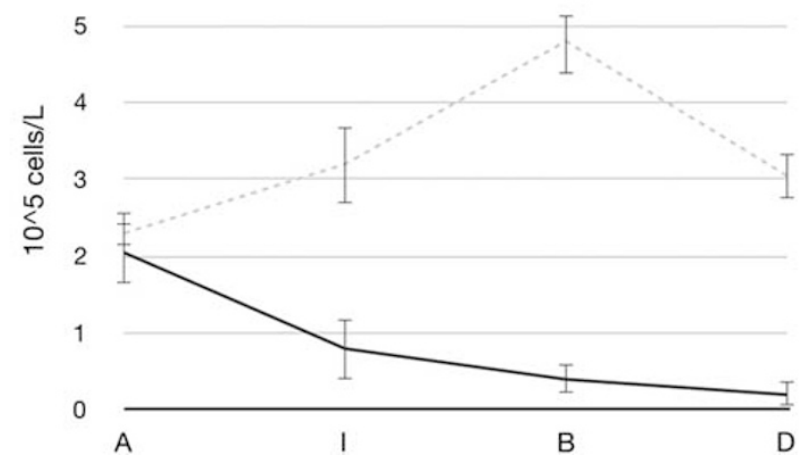

Figure 1 Scanning electron micrographs of protists from the Cariaco Basin's anoxic, sulfidic, deepwaters (900 m). (a-d) Flagellates; (g-i) possible scuticociliates with (e, f) epibiotic bacteria. Scale bars: $2 \mu \mathrm{m}(\mathbf{c}, \mathbf{e}, \mathbf{f}), 5 \mu \mathrm{m}(\mathbf{b}, \mathbf{d}, \mathbf{h}, \mathbf{i}), 10 \mu \mathrm{m}(\mathbf{g})$ and $20 \mu \mathrm{m}(\mathbf{a})$. (j) The number of protistan cells visualized by FISH with a 'universal' eukaryotic probe (solid line) versus their total number determined by SEM (dotted line). A: $40 \mathrm{~m}$ above the oxic/anoxic interface, I: interface (approximately $250 \mathrm{~m}$ depth), B: $40 \mathrm{~m}$ below the interface, D: $900 \mathrm{~m}$. B, epibiotic bacteria; CC, caudal cilia; F, flagellum; FU, furrow; PM, paroral membrane; PS, pseudopodia; SK, somatic cilia; V, vestibulum.

line of evidence for the presence of live protists in this habitat, whereby reverse transcription led to detection of short-lived 18S rRNA. This revealed an abundance of likely live and active cells in the deep anoxic layers of the Cariaco Basin, such as ciliates (Figure 2), fungi and stramenopiles. Our observation of many diverse and novel ciliate phylotypes is in line with earlier molecular surveys of the Cariaco Basin (Stoeck et al., 2003b).
Despite these advances, the questions remained, 'Was there anything particularly special about the anoxic depths of the Cariaco? Were these habitats somehow enriched with novel protists? And if so, to what extent?'. To address these questions is a challenge, but should be possible using a combination of SEM and FISH (Stoeck et al., 2003a; Kolodziej and Stoeck, 2007). Counting intact cells on SEM preparations, which is rarely done because 


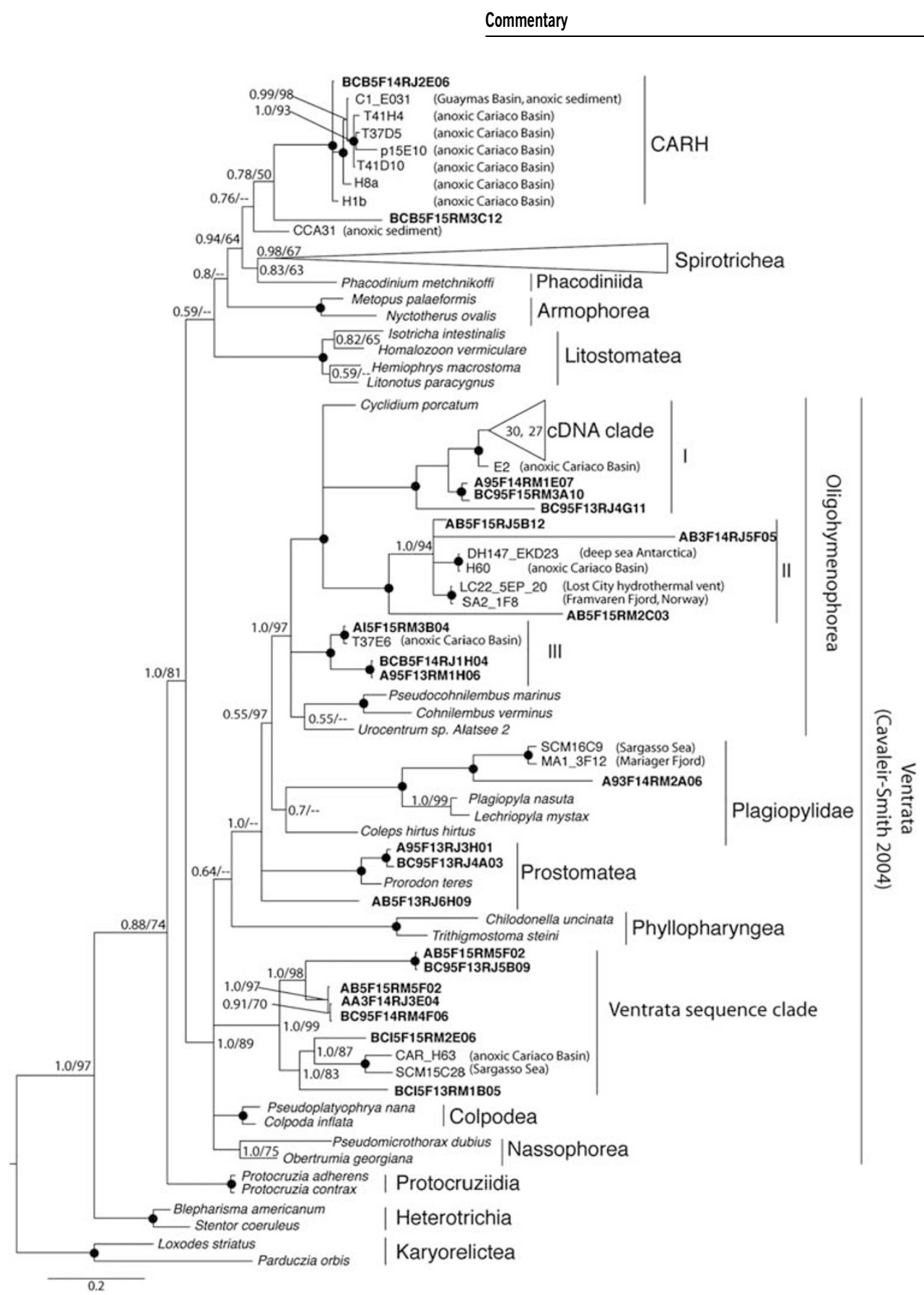

Figure 2 Phylogenetic relationships of ciliate 18S rRNA gene sequences obtained by the cDNA approach, as well as direct amplification of the gene from environmental samples. Bootstrap (RAxML) and posterior probability values greater than $50 \%$ are shown at the nodes in the order PP/ML. Black circles at the nodes represent full posterior probability and bootstrap support. Centroid sequences from our $18 \mathrm{~S}$ rRNA gene survey (see Edgcomb et al. (2011) and Orsi et al. (2011)) are in bold font. All cDNA sequences fell into the 'cDNA clade'. The number of cDNA sequences and those from our 18S rRNA gene survey are shown in the collapsed triangle (30 cDNA sequences, $2718 \mathrm{~S}$ rRNA gene sequences).

it is so labor-intensive, would provide arguably the best possible total cell count. FISH with a universal eukaryotic probe such as euk1209R (Giovannoni et al., 1988) performed on the same preparations would provide an approximation of the number of cells belonging to known species. Given the fact that such probes are designed on the basis of known sequences, mismatches in target binding sites would be more likely to occur in previously undiscovered organisms. Thus, the ratio between the FISH and SEM counts provides insight into the relative fraction of known to total protists in the sample.

We compared such fractions for samples collected at four depths, from the fully oxygenated upper to highly sulfidic 900-m-deep layers (Figure 1j). Expectedly, SEM counts exceeded those obtained by FISH in all samples, as no single universal FISH probe is perfect. However, such a probe could 
be expected to visualize the majority of cells in better-studied habitats, such as the ocean surface, toward which such probes are biased. Predictably, $91 \%$ of cells from the oxygenated layer were detected in our FISH/SEM assay (Figure 1j). However, we were surprised by a dramatic drop in the ratio of FISH-to-SEM detected cells with depth, down to mere $6 \%$ in the most sulfidic samples (Figure 1j). The likeliest explanation is that the more the rRNA novelty that was contained in the progressively deeper samples, the more the organisms that the conventional rRNA-based technique missed. This is indirectly supported by the following observation. In silico, over $40 \%$ of OTUs that we detected in anoxic samples, and clustered at $99 \%$ sequence identity level, have at least one mismatch with the $1209 \mathrm{R}$ probe binding site: 15 out of 39 OTUs in the cDNA dataset, and 313 out of 765 in the rRNA gene sequence dataset (the latter is published in the two companion papers in this issue by Edgcomb et al. (2011) and Orsi et al. (2011)). Indeed, the shortcomings of rRNA probes targeting diverse microbial groups are well known (Lucker et al., 2007), and some evidence suggests that a conventional application of the rRNA approach likely accesses only half of the microbial eukaryotic diversity (Jeon et al., 2008). On the other hand, because rRNA copy number is an indication of microbial growth and activity (Klappenbach et al., 2000), it is also possible that some of the cells seen by SEM but missed by FISH had low ribosome content, growth rates, or were dead. We consider this rather unlikely because, for the last possibility, such cells must be dead yet look alive and remain intact, which is almost impossible for naked protists (surrounded only by a cell membrane). Finally, it is possible that our probe did not penetrate the cell membrane of the majority of cells from the deepest samples. However, how likely is it that probe exclusion explains low hybridization efficiencies considering that the majority of cells at this depth are comprised of naked cells? We conclude that it might indeed be possible that the majority of protists from this deep anoxic layer are divergent at this 'universal' eukaryotic FISH probe binding site. It follows that it is equally possible that most of these protists would not be recovered using available eukaryotic PCR primers either. Thus, many of our SEM observations may represent truly novel organisms that had escaped detection to date by standard molecular approaches. Techniques free of PCR biases, such as metagenomics and metatranscriptomics, might provide access to this unknown source of diversity but these have yet to be applied to communities of microbial eukaryotes. These results also highlight a need to renew efforts in direct observation and novel cultivation methods. Traditional microscopy approaches seem to have fallen out of fashion, but clearly remain invaluable, especially as a synergy between as-transmitted light, fluorescence and electron microscopy observations, particularly for exploring taxa rich in morphological characters.

This brings us back to our original point. Although admittedly preliminary, the most critical data discussed here were obtained exclusively because we were able to fix cells in situ. We note that even 'simple' fixation in situ was not a trivial exercise, and actual in situ experimentation will be all the more difficult. However, if results and surprises to date are any indication, this might be well worth the effort.

\section{Acknowledgements}

We thank the captain and crew of the B/O Hermano Gines and the staff of the Fundación La Salle de Ciencias Naturales, Margarita Island, for their assistance during our fieldwork in Venezuela. We thank particularly Yrene Astor and Ramon Varela for their strong logistical support during our sampling. We are grateful to Mary I Scranton and the dedicated researchers of the CARIACO biogeochemical time series program, without whom this work would not have been possible. This research was supported by grants from NSF (MCB-0348341 and DEB0816840 to SE, MCB-0348407 to VE and OCE 03-26175 and MCB-03-47811 to GTT). This is contribution no. 270 from the Marine Science Center, Northeastern University, Nahant, MA, USA. The cDNA sequences from this study have been deposited in GenBank with the accession numbers HM443081-HM443437.

$V$ Edgcomb is at Department of Geology and Geophysics, Woods Hole Oceanographic Institution, Woods Hole, MA, USA;

$W$ Orsi is at Department of Biology, Northeastern University, Boston, MA, USA;

$G$ Taylor is at School of Marine and Atmospheric Sciences, Stony Brook University, Stony Brook, NY, USA;

$P$ Vdacny is at Department of Zoology, Comenius University, Bratislava, SK, Slovak Republic; $C$ Taylor is at Department of Biology, Northeastern University, Boston, MA, USA;

P Suarez is at Departamento de Biología de Organismos, Universidad Simón Bolivar, Sartenejas, Baruta, Estado Miranda, Venezuela and $S$ Epstein is at Department of Geology and Geophysics, Woods Hole Oceanographic Institution, Woods Hole, MA, USA; $S$ Epstein is at Marine Science Center, Northeastern University, Nahant, MA, USA. E-mail: slava.epstein@neu.edu

\section{References}

Edgcomb V, Orsi W, Bunge J, Jeon SO, Christen R, Leslin C et al. (2011). Protistan microbial observatory in the 
Cariaco Basin, Caribbean. I. Pyrosequencing vs Sanger insights into species richness. ISME J; e-pub ahead of print 10 March 2011.

Giovannoni SJ, DeLong EF, Olsen GJ, Pace NR. (1988). Phylogenetic group-specific oligodeoxynucleotide probes for identification of single microbial cells. J Bacteriol 170: 720-726.

Jeon S, Bunge J, Leslin C, Stoeck T, Hong S, Epstein SS. (2008). Environmental rRNA inventories miss over half of protistan diversity. BMC Microbiol 8: 222.

Klappenbach JA, Dunbar JM, Schmidt TM. (2000). rRNA operon copy number reflects ecological strategies of bacteria. Appl Environ Microbiol 66: 1328-1333.

Kolodziej K, Stoeck T. (2007). Cellular identification of a novel uncultured marine stramenopile (MAST-12 Clade) small-subunit rRNA gene sequence from a Norwegian estuary by use of fluorescence in situ hybridization-scanning electron microscopy. Appl Environ Microbiol 73: 2718-2726.

Lucker S, Steger D, Kjeldsen KU, MacGregor BJ, Wagner M, Loy A. (2007). Improved 16S rRNA-targeted probe set for analysis of sulfate-reducing bacteria by fluorescence in situ hybridization. J Microbiol Methods 69: 523-528.

Martin W, Muller M. (1998). The hydrogen hypothesis for the first eukaryote. Nature 392: 37-41.
Muller-Karger F, Varela R, Thunell R, Scranton M, Bohrer R, Taylor G et al. (2001). Annual cycle of primary production in the Cariaco Basin: response to upwelling and implications for vertical export. J Geophys Res 106: 4527-4542.

Orsi W, Edgcomb V, Jeon SO, Leslin C, Bunge J, Taylor GT et al. (2011). Protistan microbial observatory in the Cariaco Basin, Caribbean. II. Habitat specialization. ISME J; e-pub ahead of print 10 March 2011.

Stoeck T, Fowle WH, Epstein SS. (2003a). Methodology of protistan discovery: from rRNA detection to quality scanning electron microscope images. Appl Environ Microbiol 69: 6856-6863.

Stoeck T, Taylor GT, Epstein SS. (2003b). Novel eukaryotes from the permanently anoxic Cariaco Basin (Caribbean Sea). Appl Environ Microbiol 69: 5656-5663.

Taylor CD, Doherty KW. (1990). Submersible Incubation Device (SID), autonomous instrumentation for the in situ measurement of primary production and other microbial rate processes. Deep Sea Res 37: 343-358.

Taylor GT, Scranton MI, Iabichella M, Ho TY, Thunell RC, Muller-Karger F et al. (2001). Chemoautotrophy in the redox transition zone of the Cariaco Basin: A significant midwater source of organic carbon production. Limnol Oceanogr 46: 148-163. 